\title{
O "NEGRO" NO LIVRO DIDÁTICO DE HISTÓRIA DO ENSINO MÉdIO E A LEI 10.639/03
}

\author{
THE BLACK PEOPLE IN THE HISTORY TEXTBOOK OF THE SECONDARY \\ SCHOOL AND THE LAW 10.639/03
}

Fernando Santos de Jesus ${ }^{1}$

\begin{abstract}
RESUMO: Este estudo investiga a representação do negro no livro didático de História do Brasil, em suas formas contraditórias de negação das matrizes africanas, que exclui os afrodescendentes dos espaços sociais de produção do saber através da violência simbólica, e, por conseguinte, da propagação do racismo. Analisamos um capítulo de um livro didático de história, conteúdo de História do Brasil, utilizado em escola de Ensino Médio do Rio de Janeiro, buscando analisar se os dispositivos da lei $10.639 / 03$ e as Diretrizes Curriculares Nacionais para a Educação das Relações Étnico-Raciais para o ensino de história e cultura afro-brasileira e africana estão sendo contemplados no material. Os resultados desse estudo apontam para a necessidade de ressignificação de textos e imagens da população negra nos livros didáticos, pois a invisibilidade da população negra constitui para uma possível desmobilização desse contingente populacional por não se vê-los como ativos nos processos políticos do país que cultiva o mito da democracia racial, e continua vinculando imagens pejorativas ao cotidiano de afrodescendentes sem contextualizar os motivos das condições materiais e simbólicas "inferiores" as dos brancos.
\end{abstract}

Palavras-chave: Racismo. Simbólico. Livros Didáticos. Textos e Imagens.

\begin{abstract}
This study investigates the representation of blacks in textbook History of Brazil in its contradictory forms of denial of African matrices exclude blacks from the social spaces of knowledge production by irradiation of symbolic violence, and hence the spread of racism. We do a content analysis of a chapter in a history textbook content in Brazil's history used in secondary school (Rio de Janeiro), trying to analyze whether the provisions of the law $10.639 / 03$ and the national curriculum guidelines for the education of relations racial and ethnics for teaching history and culture afro-Brazilian and African are being contemplated in the material analyzed. The results of this study indicate the need for reinterpretation of texts and images of black people in the textbooks, because the invisibility of the black population is a possible demobilization of overall population not to be seen as active in the political processes of the country that cultivates the myth of racial democracy, but still linking to the daily derogatory images of black without contextualizing them on the grounds of material and symbolic conditions below those of whites.
\end{abstract}

Keywords: Racism. Symbolic. Textbooks. Text and Images.

\footnotetext{
${ }^{1}$ Especialista e Mestrando em Relações Étnico-Raciais e Educação pelo CEFET/RJ.
} 


\section{Introdução:}

Após promulgação da lei 10.639/03 observam-se muitas produções de livros e materiais, didáticos e paradidáticos, que contribuem com a valorização de textos e imagens dos negros no intuito de desmistificar alguns estereótipos desse grupamento populacional.

Essa lei visa à obrigatoriedade de inserção dos conteúdos de história e cultura afro-brasileira e africana em disciplinas de todos os segmentos de ensino. Contudo, para nós, somente os conteúdos da lei não bastam, pois os mesmos devem ser expressos de forma valorativa, no que concernem às construções das representações culturais, textuais ou imagéticas, de africanos e afro-brasileiros no cotidiano escolar e nos materiais a serem utilizados no fazer educativo.

No ano de 2008, o Fundo Nacional de Desenvolvimento da Educação (FNDE) disponibilizou uma gama de livros sobre a temática racial para distribuição em escolas da rede pública de ensino, tanto nas redes municipais e estaduais. As primeiras trabalham na maioria das vezes com a educação básica em nível fundamental e as segundas majoritariamente com o ensino médio.

Nesse sentido, pensamos se a distribuição desses livros e materiais, didáticos e paradidáticos, contempla a necessidade aventada pela lei, pois amiúde, seria vago demais afirmar que a lei n. 10.639/03 estaria dando conta do seu propósito em todos os livros editados após sua promulgação. Por esse motivo, pretendemos analisar o conteúdo de um livro didático utilizado em uma escola da estadual do Rio de Janeiro, entendendo que os estudantes do terceiro ano do ensino médio estão em fase de forte interiorização dos valores que a eles são apresentados em diversas instâncias, devido às escolhas acerca das profissões, levando as práticas sociais que desdobrarão após a inserção nas mais variadas carreiras e instancias do cotidiano.

Assim, utilizamos como fonte de pesquisa o capítulo treze (História do Brasil Contemporâneo) de um material de divulgação da editora Scipione de História Geral e do Brasil em seu terceiro volume publicado em sua primeira 
edição no ano de 2011 no estado de São Paulo, escrito pelos autores; Cláudio Vicentino e Gianpaolo Dorigo.

Cabe ressaltar que a intenção do capítulo treze dessa obra é justamente a tentativa de informar que a sociedade brasileira não é uma sociedade harmônica, demonstrando através de diversos presidentes que dirigiram após a redemocratização do país os avanços e retrocessos no campo político, econômico e social.

Portanto, procuraremos explicitar ao longo do texto os avanços e estagnações que a obra traz em seu bojo, demonstrando o quão difícil é fugir das questões impostas pela criação e irradiação de verdades sobre o negro $^{2}$ com seus usos e fazeres culturais (quando está de fato visível), imposto por um sistema enunciativo hegemônico branco e ocidentalizado, mesmo quando se tem a intenção de trabalhar valorativamente a questão da construção de uma sociedade realmente democrática.

\section{A Construção Ocidental do Imaginário Social Acerca do "Negro"}

Partindo da leitura da referida obra percebe-se a intenção de desconstrução e reconstrução do imaginário social brasileiro a partir da discussão acerca da política, estabelecendo uma relação de causa e efeito acerca das decisões tomadas em âmbito político, tendo seus efeitos reverberados no social.

Nesse sentido, a obra revela despreocupação com os elementos simbólicos como contribuidores para o nível de tensões sociais que vive o Brasil, mesmo após a redemocratização da política. Tal reflexão não é apresentada, pelos autores, e para nós, se dá forjando de maneira positiva a participação da população de maneira geral nas reivindicações populares, não sendo necessárias reivindicações particularistas, pois as políticas

\footnotetext{
2 Utilizaremos a palavra "negro" para designar o afro-brasileiro ou o afrodescendente, no entanto, sem conotação pejorativa. Da mesma forma com a palavra "raça" ao invés de "etnia".
} 
públicas reivindicadas em âmbito geral já dariam conta de atender as demandas de todos.

Dessa maneira a identidade que aqui discutimos está pautada em como se constrói e se assimilam as normas de sociabilidade, pois nas imagens encontradas sobre os negros no livro faz com que se internalize uma construção pejorativa sobre a condição social do negro, que não é apresentado em momento de reivindicação ou em nenhuma posição de tomada de decisão da sociedade, quando sabemos que esse grupo racial participa (ou) ativamente de toda construção histórica na nação.

Corroboramos com Muniz Sodré (2000) acerca das representações sociais e os usos das normas de sociabilidade no sentido da construção signica irradiada por aqueles que possuem o aparato técnico hegemônico de massificação dos discursos, que em primeira linha se assume como verdades incontestes, de extrema dificuldade quanto à desconstrução. Diz ele que

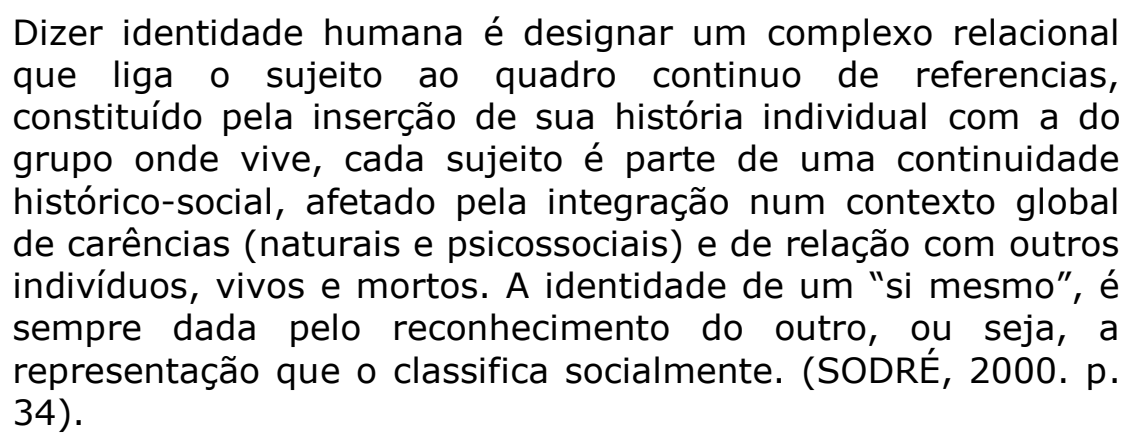

Fica patente que em relação à população negra, faltam referenciais positivos nos meios técnicos de irradiação de ideias e imagens, para que se faça um reconhecimento satisfatório de sujeitos, contestando um padrão estético e moral imposto por uma orbita que "não é a sua". Ou seja, sua "essência" é negada e construída a partir de discursos de alteridade.

Numa discussão filosófica Heidegger (1976) nos informa que o eidos designa a experiência de um vir a presença de um ente e nela permanecer, o que significa que o ser só se transforma em pessoa no contato com o ente, que não seria uma imagem esvaziada de toda presença concreta, conforme nos indica o uso do eidos, que é o termo que designa o 
enunciador do agente viabilizador do se transformar em ser. Ele nos diz que: "Ser algo é permitir-se ser compreendido sob o ângulo de algo que se mostra previamente - o "comum a vários" ou universal. O comum a vários é aquilo que previamente sobressai e se oferece a nós: a evidência". (HEIDEGGER, 1976, p.4).

Nesse sentido, retomamos a ideia de que uma ontologia do ser não pode ser confundida com o tornar-se pessoa. Essa afirmação indica que o ser traz consigo uma essência primeira que se equaliza com outros entes que trazem consigo suas essências e assim formam cultura.

Ainda em Heidegger (1973) temos a questão da ontologia inscrita na noção de ipseidade que quer dizer, o mesmo, em contraponto com o Idem que diz respeito ao idêntico, ou ao próprio pertencimento. $O$ idem seria algo que não é o mesmo, mas é nitidamente idêntico ao mesmo. Ao contrario o ipse não seria idêntico e nem parecido com o mesmo, pois já é o mesmo. Desse modo, $A=A$ diz respeito ao idem, dois As idênticos, e $A$ é $A$ diz respeito ao ipse, A significa ser ele mesmo.

Problematizando esse caráter filosófico de buscar entender a criação identitária e o jogo de alteridade inscritos na transição do ser "anômico" para a pessoa cultural, podemos inferir que os homens possuem em si a característica primeira do ethos buscando que o outro compreenda os seus enunciados a fim de fazer seus desejos e necessidades satisfeitos numa criação de alteridade, onde o outro será imaginado pré-discursivamente gerando a força motriz para as representações que, supostamente, serão conformadas pelo outro.

Compreendemos que essas estratégias discursivas são recebidas de diversas maneiras por aqueles a quem se destinam os enunciados. Nem sempre há conformação, assim como nem sempre há inconformidade. Tudo depende de complexos relacionais ligados à própria ontologia e as estratégias de resistência frente a situações que nem sempre se resolvem pragmaticamente.

Mas o que tem a ver a discussão racial com as problemáticas de conceituação filosófica do homem? Tudo, pois com as tentativas de imposição de discursos nas sociedades ocidentais a fim de se beneficiar no 
jogo de poder (econômico, político e social), houvera a conceituação de fenômenos culturais de homens com determinadas marcas e, também, a tentativa de essencializar e estigmatizar esses homens com discursos inferiorizadores.

Para tal feito, construções e circulação de verdades foram viabilizadas por aqueles que se pretenderam enunciadores de discursos, o que não significa que aqueles que foram classificados pela força hegemônica permaneceram conformados na condição de alteridade $^{3}$ e assimilaram passivamente as conceituações proferidas a eles. Heidegger (1973) assevera que

O intelecto somente é conforme com a idéia porque realiza a adequação do que pensa com a coisa, tendo esta que ser conforme com a coisa. A possibilidade da verdade do conhecimento humano, se funda se todo ente é "criado", sobre o fato de a coisa e a proposição serem igualmente conformes com a idéia e serem, por isso, coordenados um ao outro a partir da unidade do plano da criação. (HEIDEGGER, 1973, p.332).

Daí se percebe que a construção significativa dos negros foi materializada pelo pensamento ocidental que buscou ao longo de vários momentos na história, demonstrar a realização do ser negro no mundo, mas num primeiro momento como construção de ser e não de pessoa, devido a animalidade na qual descreviam esse contingente. Mais adiante se admitiu a condição de ente do negro, mas numa construção de alteridade, onde os discursos ainda continuavam a designar pejorativamente os negros, como seres humanos inferiorizados numa hierarquia onde o branco ocupa o topo da pirâmide e estaria outorgando humanidade através de sua cultura superior e de seus padrões estéticos.

Conforme tratamos anteriormente a conformidade nem sempre se faz presente numa questão diametral, e nem em uma situação de suposta igualdade enunciativa. Heidegger (1973) diz que: "Uma ação obviamente não se pode realizar a não ser através da liberdade de quem age. O mesmo

\footnotetext{
${ }^{3}$ Não se pode perder de vista que na concretude social e na luta contra hegemônica está marcadamente quem se institui como o eu e a quem esse eu designa a condição de outro, o que não significa que o outro também se veja como outro.
} 
acontece com a ação de enunciar apresentando, e com a ação de consentir ou recusar uma verdade" Liberdade segundo o mesmo autor é "O fundamente da possibilidade intrínseca da conformidade porque recebe sua própria essência da essência mais original da única verdade verdadeiramente essencial" (HEIDEGGER, 1973, p.333).

Diante do que Antônio Cândido apud Gislene dos Santos, chama de crime ontológico, o racismo no Brasil, corroboramos com os autores dizendo que a tentativa de aniquilar a ontologia do negro brasileiro se inscreve numa questão de fato social, pois ao nascer ${ }^{4}$ o repertório possível para o negro se identificar ${ }^{5}$ nada tem a ver com sua ancestralidade ou sua ontologia, pois o referencial é todo do mundo ocidental e dos brancos. Fica quase que impossibilitado, dessa maneira, que o negro exerça sua liberdade, sua essência original.

O manifesto ao qual se conforma a enunciação apresentativa, enquanto lhe é conforme, é o ente assim como se manifesta para e por um comportamento aberto. A liberdade em face do que se revela no seio do aberto deixa que cada ente seja o ente que é. A liberdade se revela então como o que deixa ser o ente. (HEIDEGGER, 1973, p.336).

As tentativas de essencializar e categorizar o negro no mundo ocidental têm como um princípio uma estratégia de fazer se identificar, conforme vimos mais atrás. As verdades veiculadas precisam, necessariamente, ser legitimadas para que dentro do espaço social determinado (pela coerção social) seja possível se socializar.

Refuta-se numa órbita em que a razão ocidental impera sobre todos os discursos contrários as suas imposições de verdades, tudo aquilo que traz a tona o desejo de liberdade do negro, pois os negros ainda não são sujeitos de sua própria história, e muitas vezes quando o são ainda são

\footnotetext{
${ }^{4}$ Concepção de Émile Durkheim que diz que o sujeito chega ao mundo numa condição de ser interpelado por um conjunto de normas e regras preexistentes ao qual ele tem, também, o poder de corroborar ou contestar contribuindo para a manutenção ou as mudanças estruturais ou conjunturais da sociedade.

${ }^{5}$ Buscar sua identificação, ou o seu idem, em outros entes e a cultura que se assemelham com sua essência ou sua ipseidade.
} 
afetados pela orbita ocidental de pensamento ${ }^{6}$. A cultura e a religião ${ }^{7}$, em especial, são contrapontos interessantíssimos se pensarmos na matriz africana de pensamento que não se pretendem como unívocas e nem como algo conceituável pela lógica ocidental. O segredo das coisas é jogo que mantém viva a cultura afro-brasileira.

Insistimos que a marginalização da cultura afro-brasileira está visceralmente entrelaçada ao poder de enraizamento das verdades criadas pelos cânones da cultura europeizada, e como o pensamento identitário brasileiro utilizou-se desses conteúdos para buscar explicar a nação, silenciando vozes e determinando quais os discursos convenientes para a possível coesão do país e o silenciamento das vozes que se manifestaram e se manifestam com uma agenda anti-hegemonia.

Voltamos a evocar a teoria de Heidegger para buscar uma compreensão de como esses discursos são possíveis. Na constituição do que se enuncia como verdade a possibilidade de oposição da afirmação do que se pretende como verdadeiro se constitui como uma não-verdade, ou algo que é classificado como falso. O filosofo exemplifica demonstrando que

\begin{abstract}
"É uma verdadeira alegria colaborar na realização dessa tarefa". Queremos dizer se trata de uma alegria pura, real. O verdadeiro é o real. Assim falamos do ouro verdadeiro distinguindo-o do falso. O ouro falso não é realmente o que aparenta. É apenas uma "aparência" e por isso irreal. O real passa pelo oposto do real. Mas o ouro falso é, contudo, algo real. É assim que dizemos mais claramente: O ouro real é o ouro autêntico. Mas um e outro são "reais", o ouro autêntico não o é nem mais nem menos que o falso. O verdadeiro do ouro autêntico não pode ser, portanto, ser simplesmente garantido pela sua realidade. (HEIDEGGER, 1973, p.331).
\end{abstract}

\footnotetext{
${ }^{6}$ Não queremos dizer com isso que não haja um grande número de negros professores doutores e pesquisadores da temática racial dentro e fora das universidades produzindo conhecimento, mas a questão é de como essas vozes possuem poder de irradiação e em que medida são elas silenciadas, ou até mesmo trabalham dentro de uma órbita que não contribui para o avanço da identidade negra, por estar afetada por um referencial que impossibilita a essência do negro aflorar, nos termos de Guerreiro Ramos "A aculturação é tão insidiosa que ainda os espíritos mais generosos são por ela atingidos e, assim domesticados pela brancura, quando imaginam o contrario". (RAMOS, 1966, p.131).

7 Entendemos que há a possibilidade de articulação entre cultura e religião entendendo que de desdobramentos religiosos surgem os mais variados aportes culturais, que aparecem nos terreiros das religiões afro-brasileiras, mas que na realidade são realizações ancestrais inteligíveis se manifestando no plano sensível. Ver Muniz Sodré. Samba o Dono do Corpo. Rio de Janeiro: Editora Codecri, 1979.
} 
Está expresso nessa concepção que o valor é dado sem algo que privilegia a essência da existência, ou a liberdade de algo. O valor de algo é designado pelo bel prazer e conveniência de quem constrói o significado. 0 que não exclui a verdade do outro que recebe a significação, com suas concepções valorativas próprias.

A não-verdade da proposição (não conformidade) é a não concordância da enunciação com a coisa. A não-verdade da coisa (inautenticidade) significa o desacordo de um ente com sua essência. A não-verdade pode ser compreendida cada vez como não estar de acordo. Isto fica excluído da essência da verdade. É por isso que a não-verdade, enquanto pensada como parte contrária da verdade, pode ser negligenciada quando se trata de apreender a pura essência da verdade. (HEIDEGGER, 1973, p.332).

Nesse sentido, os movimentos contrários aos cânones da verdade irradiada pelos sistemas hegemônicos, que não contemplam a essência (a liberdade) do negro, são marginalizados e vistos como argumentos não verdadeiros, ou seja, são argumentos falsos. Isso justifica os movimentos contrários às cotas para negros nas universidades e a predatória circulação dos padrões europeizados de estética com seus significados sobre o que seja profano ou sublime, pois seria fundamental para o ser humano evitar os constrangimentos de ser classificado negativamente por afiliação a essas não-verdades que carregam as marcas do profano e da inautenticidade.

Gislene Aparecida dos Santos (2004) conceitualmente com proposições que levam a reflexões sobre as relações inter-raciais, pois em muitos casos as condições sociais diametralmente construídas entre negros e brancos contribuem para que em momentos cruciais onde o eu branco possa se sentir ameaçado em relação à alteridade, o leva a crer que o outro não possua legitimidade na relação, passando, assim, o eu hegemônico branco a ser o dominador dessa relação. Da mesma maneira o negro, na maioria das vezes, introjeta a condição de outro e passa a agir submissamente em relação ao eu do branco, pois esse branco seria a figura do ideal atingido que dá acesso as benesses sociais e a não vinculação a 
não-verdade. Assim, os movimentos negros seriam indicados na direção dessas desconstruções dos discursos de verdades unívocas, pois lá a "essência" dessas pessoas "pode aflorar" e o reconhecimento seja parelho, onde o ipse é levado em consideração e o idem seja realmente idem, e não algo forjado para que seja idêntico ${ }^{8}$.

Nessa dinâmica não podemos perder de vista que os movimentos negros não incorrem na lógica hegemônica de produção de verdades, mas de significações contra hegemônica. O sentido de liberdade não está somente ligado à ausência de constrangimentos na direção do que impede ou que leva uma pessoa a praticar ações determinadas. Liberdade é a manifestação da essência do ser, pois a liberdade abandona a ideia de desvelamento do ser, ou de conceituação do eu em relação ao outro.

Antes de tudo isto (antes da liberdade "negativa" ou "positiva"), a liberdade é o abandono ao desvelamento do ente como tal. O caráter de ser desvelado do ente se encontra preservado pelo abandono ek-sistente; graças a este abandono, a abertura do aberto, isto é, a "presença" (o "aí"), é o que é. (HEIDEGGER, 1973, p 336).

A liberdade do negro se manifestar enquanto o como se é, numa sociedade de significações e determinações, pressupõe luta contra um sistema opressor que tenta classificá-lo, e somente no seio de ações coletivas que buscam desvelar os fatores de desmobilização e de morte ontológica do negro, se faz o movimento contrário, pois ao desvelar essas condições se abre espaço para que se possa manifestar a liberdade do ser negro, inscrito na sua ancestralidade e na continuidade do corpo e da mente.

Assim, voltamos à questão da essência da verdade que não se inscreve na criação mecânica de signos que se pretendem como únicos e com valores legítimos em contraposição aos valores ilegítimos daquilo que se pretende dar a conotação negativa. A verdade aqui trabalhada é a essencial, ou seja, o homem carrega em sua essência a verdade, a

\footnotetext{
${ }^{8}$ Estamos falando do processo de assimilação cultural e das próprias maneiras de mutilação do próprio corpo para conseguir ser idêntico ao branco, no vértice do padrão de idealização.
} 
liberdade é a verdade, o homem não possui a verdade, mas está impregnado dela anteriormente a criação dos significados de verdade. Por esse motivo a não-verdade é verdadeira.

Portanto, buscamos demonstrar que a concepção ocidental de pensamento buscou através da complexidade de enunciações, conceituar o negro em uma orbita negativa nas relações, onde estética e cultura negra se equalizam num conjunto marginalizado de signos ilegítimos ou falsos dentro dos cânones da cultura objetivada pelas classes que detém o poder. Essas criações acabam por contaminar, em certa medida, um conjunto populacional amplo que incluem brancos e negros na assimilação e conformidade daquilo que por eles são prescritos na tentativa de determinar as normas societárias.

\section{As Diretrizes Curriculares Nacionais para a Educação das Relações Étnico-Raciais e para o Ensino de História e Cultura Afro-Brasileira e Africana}

As Diretrizes Curriculares para a Educação das Relações Ético-Raciais e para o Estudo de História e Cultura Afro-Brasileira e Africana foi formulada para que todos os cidadãos brasileiros possam gozar de uma educação que contemple as variadas formas de se conceber o surgimento da nação no que concernem aos aportes culturais existentes nos povos fundadores da nação. Assim, os elementos culturais criados pelos africanos e seus descendentes precisariam ser revistos e melhor trabalhados, desvelando um caráter racista na forma de como esses conteúdos foram dados ao longo dos tempos nos bancos escolares em todos os níveis de ensino, perdurando até os dias de hoje, trazendo efeitos negativos para a população como um todo, sobre tudo a população negra.

Nota-se desde o início do documento que alguns estados se atentaram para a efetivação de uma educação que contemplasse os conteúdos de história e cultura negra, bem como os estudos acerca das condições que a discriminação racial poderia acarretar na sociedade. Percebemos, portanto, que os estados que adotaram tais medidas foram 
estados onde a maciça presença de negros possibilitou a assunção de reivindicações acerca de uma educação de qualidade e antirracista.

Corroborando com ideia citada anteriormente, podemos dizer que em todo o documento está expresso que a lei n. 10.639/03 fora a mola propulsora para atender a população afro-brasileira no anseio de ter sua história reconstruída (nos livros didáticos e bancos escolares) e valorizada, destituída dos estereótipos do passado, que causam nefastos efeitos psicológicos a população negra, que incorpora os arquétipos expressos em materiais didáticos e no próprio fazer educativo, o que objetivamente, impede, ainda hoje, a ascensão social do negro. Portanto, a lei foi um avanço nas discussões do movimento negro, constituindo em uma grande vitória.

O documento caminha na direção propositiva de criar subsídios para que a sociedade como um todo possa ser educada e ter acesso a materiais que possibilitem no aprendizado a lidar com a diversidade étnico-racial existente, pois os antigos conteúdos não davam conta de como realmente sejam as questões raciais e os seus desdobramentos sociais, tornando difícil conseguir justiça social devido à fluidez do discurso da democracia racial.

Os conteúdos das diretrizes dialogam diretamente com alguns saberes da população do continente africano e com a diáspora africana no mundo, no intuito de fortalecimento dos laços culturais de origem africana, pois mesmo concebendo que a cultura pode se tornar hibrida no contato entre os povos, ela tem está inscrita em um local que reivindica a legitimidade de nascimento, e que somente em outro momento e contato com outra manifestação se tornará hibrida. Essa assertiva traz à tona a valorização de tudo que seja de matriz africana e que comumente é associado a coisas negativas, como a religião, a música, a indumentária e etc. Todo esse esforço é canalizado para que a sociedade seja reconstruída em bases justas, onde o negro possa viver em iguais condições materiais, psicológicas e educacionais que os demais membros da nação.

O documento prevê toda a logística para que seja possível a realização dessa empreitada, pois se é sabido que os profissionais da educação ainda precisam ser mais bem qualificados para lidar com essa 
questão, tendo em vista a resistência da academia a lidar com a questão racial dispondo de baixos recursos financeiros e, por conseguinte, de uma produção bibliográfica insuficiente, aliado ao fato de a lei ser bastante recente, pois antes dela o assunto era mitigado justamente por não haver nenhum dispositivo legal que obrigasse as instituições de ensino a tratar da questão racial. Somente tínhamos os preceitos da constituição de 1998, que ajudou na leitura para a formulação de tais medidas.

Portanto, com a aprovação do conselho nacional para as Diretrizes Curriculares Nacionais para a Educação das Relações Étnico-Raciais e para o Ensino de História e Cultura Afro-Brasileira e Africana temos a viabilização de várias fontes de pesquisa e de documento que oriente as instituições de ensino e os indivíduos envolvidos com o fazer educativo na construção dos seus currículos indicando como os conteúdos devam ser trabalhados.

\section{Analisando o Livro Didático}

Antes de tudo é mister contextualizar nossa escolha pelo livro analisado, pois assim o leitor desse estudo pode compreender nossa inquietude e os motivos que nos levaram a obra escolhida.

Escolhemos o livro didático de ensino médio (mais precisamente utilizado no terceiro ano do ensino médio) por pensarmos que seja o período no qual o jovem fará suas escolhas profissionais e começará a lidar mais diretamente com o mercado de trabalho e com as diferenças éticoraciais na dinâmica de hierarquia trabalhista. Por esse motivo, acreditamos que se os livros didáticos do ensino médio, aliado ao fazer educativo, não consiga explicitar as causas que levam à significação pejorativa do negro na sociedade, ou simplesmente omitem as informações que levam a exclusão do povo negro do produto social, as relações sociais dos indivíduos na escolha de suas carreiras e seus próprios cotidianos estarão debilitadas em relação à sensibilidade racial e a criticidade quanto à "democracia racial" em que vivemos. 
O livro escolhido constitui um material de divulgação da editora Scipione de História Geral e do Brasil em seu terceiro volume publicado em sua primeira edição no ano de 2011 no estado de São Paulo, escrito pelos autores; Cláudio Vicentino e Gianpaolo Dorigo. Ambos são professores de cursos pré-vestibulares e autores de livros didáticos para o ensino médio.

Nossa análise do material escolhido fica restrita ao capítulo treze; 0 Brasil no Século XXI, por entender que esse, seja o capítulo que constitua uma história bem recente e, talvez, mais acessível aos alunos dos anos finais do ensino médio, pois acreditarmos que conhecer os fatores históricos, sociais e políticos contemporâneos de nossa sociedade aflore a consciência critica dos alunos os tornando em cidadãos engajados nas lutas contra qualquer tipo de discriminação e opressão.

Esse capítulo está disposto desde a página 257 até a página 281 contando com uma gama de exercícios de vestibulares de universidades públicas e privadas no final a fim de auxiliar o aluno a fixar o que os professores utilizaram no cotidiano escolar. Os exercícios vão desde a página 282 até a página 297 do livro.

No nosso entender o intuito do capítulo é informar de forma organizada e temporal o agravamento das tensões políticas, econômicas e sociais, através da apresentação de como cada um dos governos após o regime militar chegando aos governos que adentraram o século XXI no comando da nação lidaram com as demandas sociais através das políticas públicas e de governo que se espera de um país de sistema democrático com uma constituição dita como cidadã e mais democrática de todos os tempos, a de 1988.

No longo da apresentação do capítulo as abordagens são as mesmas; demandas econômicas, políticas e sociais; e como os governos lidam com esses problemas tendo em vista uma conjuntura internacional que pressiona os países periféricos como é o caso do Brasil, no que tange aos órgãos de financiamento para crescimento econômico e para políticas de bem estar social.

Cada governo é apresentado sendo necessária uma contextualização de final do século XX para poder entender os resquícios que cada governo 
herdou do anterior e da ditadura militar para carregar o fardo de buscar equalizar os problemas políticos, sociais e econômicos do Brasil.

Esse caráter é explicitado logo na primeira parte do capítulo (página 357), onde os autores advertem para o que será tratado adiante, explanando sobre a constituição de 1988 e quais as posições criticas direcionarão os estudos do livro na problematização dessa constituição em relação à efetivação pragmática dos direitos ali expressos.

Na página 258 os autores contextualizam a modernização do país (trabalhada no capítulo anterior) e direciona o escopo a ser trabalhado. Interessante localizarmos nesse início de capítulo que os autores possuem as características que compõe a base do pensamento de esquerda de outrora, que infere que os atrasos sociais, políticos e econômicos brasileiros provêm dos setores mais conservadores ditos de direita.

Fica claro, portanto, para o leitor que o livro seguirá um direcionamento de contestação aos sistemas ditos opressores no uso e desuso das riquezas nacionais as quais se tornam fruto de usurpação de uma minoria em detrimento uma maioria que vive no clamor de melhores condições de vida. Nesse sentido, é privilegiado no trabalho dos autores os movimentos sindicais e estudantis que vão às ruas e buscam soluções para os problemas econômicos na contestação da figura de determinados políticos que seriam os protagonistas da "desordem" social brasileira.

A crítica que tecemos a essa visão é a de que os autores acabam não evidenciando outras militâncias tão importantes para determinados setores e atividades especificas. Esse silenciamento, esquecimento, tendenciosidade ou ingenuidade (não há como saber), não são muito bem vistos, pois não veicular que variadas vozes excluídas buscaram amplificar seus anseios acabam por inviabilizar que sujeitos que não possuem o acesso a determinados estudos específicos dentro da academia conheçam estudos que venham a criticar e refutar os cânones históricos de cultura e irradiação de verdades ocidentalizadas. Além disso, é relevante deixarmos claro acerca da massificação que 
Querer especificar o termo massa é justamente um contrasenso - é procurar um sentido no que não o tem. Diz-se: "a massa de trabalhadores". Mas a massa nunca é a de trabalhadores, nem de qualquer outro sujeito ou objeto social. As "massas camponesas" de outrora não eram exatamente massas: só se comportam como massa aqueles que estão liberados de suas obrigações simbólicas, "anulados" (presos nas infinitas "redes") e destinados a ser apenas o inumerável terminal dos mesmos modelos, que não chegam a integrá-los e que finalmente só os apresentam como resíduos estatísticos. A massa é sem atributo, sem predicado, sem qualidade, sem referência. Aí está sua definição, ou sua indefinição radical. Ela não tem "realidade" sociológica. Ela não tem nada a ver com alguma população real, com algum corpo, com algum agregado social específico. (BAUDRILLARD, 1978. p.4).

Por esse motivo, acreditamos que em todo o processo de "redemocratização" do Brasil o negro esteve presente buscando seu espaço na sociedade lutando contra o preconceito racial, aventando para as questões de que as mazelas sociais não possuem simplesmente sua gênese no aparelhamento político e econômico imbricando no social geral, pois os fatores simbólicos de construção de ideias e ideais são fundamentais para que a hierarquia e a alteridade se constituam.

Nessa primeira parte do capítulo treze do livro não localizamos em nenhum momento uma afirmação da situação dos sujeitos (pelo menos a maioria) que compõe o grupo dos excluídos ou do poder hegemônico. Isso para nós seria fundamental, pois sabemos que o poder, assim como o exército de excluídos, têm raça, sexo, opção sexual e religião. Portanto, acreditamos que sinalizar para essas questões faria com que, tanto alunos quanto professores, refletissem acerca de situações simbólicas pontuais que excluem uns e privilegia outros em determinados espaços estabelecidos dentro da sociedade brasileira.

$\mathrm{Na}$ página 262 os autores elencam os fatores que acreditam ser positivos da constituição de 1988 citando os seguintes:

- Democracia liberal com separação dos três poderes e eleição direta para todos os cargos do Executivo e Legislativo, prevendo-se realização a de dois turnos nas eleições dos cargos executivos mais importantes (presidente da República, governadores de estado e prefeito dos municípios com mais de 200 mil habitantes); 
- Voto obrigatório para pessoas entre 18 e 70 anos; facultativo a analfabetos, jovens entre 16 e 18 anos e pessoas com mais de 70 anos;

- Fim da censura prévia, garantia do direito de greve, liberdade sindical;

- Nacionalismo econômico, reservando-se uma série de atividades às empresas nacionais;

- Intervenção do estado na economia, atribuindo-se a ele uma série de funções reguladoras e gerenciadoras;

- Amplo assistencialismo social, garantindo-se os direitos trabalhistas;

- Descentralização administrativa e financeira, afetando estados e municípios;

- Artigos que tratam dos direitos das crianças e dos adolescentes. (VINCENTINO, DORIGO, 2011, p.262).

Conforme visualizamos nessa gama de benfeitorias da lei entendemos que os autores privilegiem políticas de bem estar social e acreditam na possibilidade de uma melhor (re) distribuição da renda com aportes advindos do contrato social com as leis que amparariam todos os sujeitos de uma mesma cidadania. Contudo, vale observar que um avanço constitucional imprescindível fora alcançado em 1988, a lei antirracismo, fato que se deve a reivindicações de entidades do movimento negro organizadas em varias instâncias e campus de atuação.

Outra leitura nos autoriza a dizer que os autores deram, novamente, bastante ênfase aos aspectos políticos e econômicos que proporcionasse algum retorno a sociedade de maneira geral, as políticas universalistas.

Por isso, novamente, gostaríamos de chamar a atenção para a não contextualização das questões educacionais nos governos trabalhados no livro, pois a situação de alfabetização e um projeto educacional sério deveriam estar contidos em uma agenda política que se dizia redemocratizada. Assim, seria de suma importância pensar em discussões curriculares, de práticas pedagógicas e de conteúdos veiculados em manuais, pois em vários materiais pedagógicos e nos currículos educacionais produzidos nesse contexto ainda apontavam para as dificuldades de (re) construção de um imaginário social que se pretendesse democrático.

É de salutar importância saber que durante a década de 1980 circulava nas escolas de ensino fundamental uma cartilha chamada O sonho 
de Talita da Editora Didática e Cientifica das autoras Manoelita Marcello Pimenta Bueno e Maria do Carmo de Freitas Guimarães. Essa cartilha foi duramente combativa pelos movimentos negros e pelo ex-senador e intelectual negro Abdias do Nascimento, pois nesse material estavam contidos diversos ataques racistas a uma personagem negra chamada Diva. Diva sempre estava presente na trama como a menina desobediente, traquina, sem família, de hábitos condenáveis pelas demais crianças em contraponto a Talita, essa sim dotada de bons hábitos, requintes e querida por todos. A autora exaltou todos os traços positivos concentrados em uma criança branca e tudo aquilo que não corresponde de bom agrado na sociedade fora atribuído a criança negra.

De alguma maneira alguns fatores como este deveriam constar no livro que estamos analisando a fim de sinalizar para leitores (alunos e professores) que o processo de marginalização, exclusão e discriminação não foi construído somente em bases econômicas e políticas, tendo papel decisório nesse processo a instituição escolar, que prescreveu, incentivou e formularam diversas formas de se pensar a sociedade, dentre elas algumas formas racistas e sexistas.

Avançando para o governo de Fernando Collor de Mello os autores descrevem todos os escândalos que permearam o cenário de corrupção subjacente ao governo desse homem. É bastante enfatizada a participação de entidades estudantis na colaboração da deposição de Fernando Collor, pois é comumente veiculada a imagem dos "caras pintadas" como uns dos grandes viabilizadores da suposta vitória do povo contra um governo corrupto.

Ora, se pensarmos com mais apuro sobre a atuação dos caras pintadas veremos, de certa forma, legitimidade nas reivindicações. Por outro lado, podemos pensar em que cenário atuavam e quais os rostos se escondiam por de traz das tintas que os camuflavam. Sob o ponto de vista da composição étnico racial dos caras pintadas nenhum censo foi feito ou nos é acessível, mas visivelmente temos uma maioria esmagadora de pessoas brancas, em detrimento os negros e os indígenas. 
O acesso às universidades sempre fora privilégio de uma parcela bem pequena da população brasileira, pois a grande maioria vive em condições de pobreza e possui baixa realização escolar. Quando pensamos na situação dos negros isso se agrava, pois conforme vários estudos demonstram a população universitária no Brasil gira entorno de menos de $10 \%$ de negros compondo as vagas, isso sem falar na evasão dos mesmos por motivos de manutenção dentro do sistema universitário, se complexificando mais ainda se pensarmos nos cursos de maior valorização social.

Pelo motivo exposto se pode pensar que o movimento dos caras pintadas não fora um movimento de bases populares, ou de uma maioria excluída das benesses sociais, pois a direção do movimento era composta por estudantes universitários e partidários a políticas contrárias ao governo que estava no poder. Assim, remetemos ao pensamento que a maioria excluída não teria tamanha força de mobilização. Queremos dizer com isso que a força de mobilização inclui aparato técnico e não descontextualização política, pois o discurso que circula é o de que a maioria dos excluídos é despolitizada.

Poderia ter sido situado no livro algum tipo de informação que, sem desqualificar o movimento dos caras pintadas, situasse o leitor acerca das condições materiais e políticas em que se encontrava a maioria da população e que o movimento dos caras pintadas, fora um movimento de jovens universitários de cunho reivindicatório em bases socialistas, mas que em certa medida encampavam alguns motivos particulares de grupos a que estavam afiliados, pois como bem sabemos o governo Collor prejudicou grande parcela de uma pequena burguesia e/ou da classe média brasileira, que por sua vez são os mesmos que podiam custear estudos para seus filhos, os que constituíam os movimentos estudantis da época.

Antes disso foram explicitados, preliminarmente, alguns motivos que levaram o presidente Collor ao poder, sendo bastante enfatizado que o mesmo estava obsoleto, até então, no cenário político brasileiro. Talvez, essa tenha sido a causa imediata de se prestar credibilidade a quem não aparecia envolvido em escândalos e corrupção e se dizia vigoroso e "caçador de marajás". 
Sabemos que um dos motivos pelo qual o presidente Collor tenha subido ao poder foi o seu marketing pessoal, pois trazia em si um "bom mocismo", uma imagem de vigor físico e intelectual. Essas imagens nada mais são do que as estratégias de se utilizar de um imaginário social construído em bases racistas, no qual se tem como simbolicamente adequado a construção de beleza ocidentalizada, ou afiliação a ela. Isso proporcionou muitos votos ao presidente de cidadãos deslumbrados com a figura de um líder jovem, educado e com traços fenotípicos europeizados.

Na página 266 os autores lançam mão de um fragmento de um artigo da autora Esther Hamburger que nele trabalha sobre a presença da televisão no cotidiano do país. Nesse fragmento a autora fala majoritariamente sobre as representações sociais contidas em telenovelas e programas de ampla circulação como os telejornais. Admite-se nesse fragmento o preconceito racial assim ensejado:

A super-representação de brancos em relação a negros e mulatos consiste em um exemplo gritante da maneira como, por omissão, os mais diversos programas televisivos contribuíram para a reprodução da discriminação racial. (HAMBURGER, 1998).

Para nós mesmo que a intenção da autora seja positiva, ainda pecou pela utilização de um termo que é fruto de muita discriminação racial e estereotipação do negro, pois o termo mulato, como bem sabemos, designa algo de negativo e não faz avançar questões de orgulho afirmativo da população negro. Portanto, para nós, esse termo deve ser erradicado do nosso vocabulário para que um imaginário social se (re) construa sem os mesmos estereótipos do passado e se efetive o respeito à diversidade.

Mesmo lançando mão de um fragmento que venha a contribuir na discussão acerca dos motivos que corroboram para que a sociedade seja tão desigual, os autores não utilizaram esses argumentos para explicar como a campanha de Fernando Collor de Mello se prevaleceu de um imaginário social que sustenta a figura positivada do bom mocismo branco ocidentalizado como estratégia de marketing para arrecadar votos. 
É certo explicar que a lei n. 10.639/03 foi promulgada no intuito de valorizar o ensino de história e cultura negra nos conteúdos e currículos das redes de ensino público e privado do país, mas não descarta a possibilidade de articulação com a valorização das lutas históricas do povo negro em âmbito nacional e os desdobramentos sociais provindos dessas reivindicações. Por esse motivo acreditamos que situar os leitores acerca dessas militâncias, contextualizando com os fatores políticos, econômicos e sociais das épocas em que se passaram os governos e as conjunturas nacionais e internacionais, venha a ser imprescindível, pois assim os professores e educandos terão acesso às informações de vozes antes silenciadas e poderão, talvez, fazer uma reflexão bem mais critica do que outrora era possível.

Avançando para os presidentes que sucederam Fernando Collor de Mello, os autores trabalharam novamente sob uma perspectiva econômica sem laurear as lutas antirracistas de movimentos negros ou sequer explicitar que algumas das causas das mazelas sociais provêm do racismo. Assim, fora trabalhado o governo de Itamar Franco e posteriormente 0 Fernando Henrique Cardoso.

Porém, na explanação sobre as condições econômicas do governo de Fernando Henrique Cardoso, encontramos uma imagem que representaria as condições sociais precárias que seriam fruto do elevado custo de vida no governo vigente.

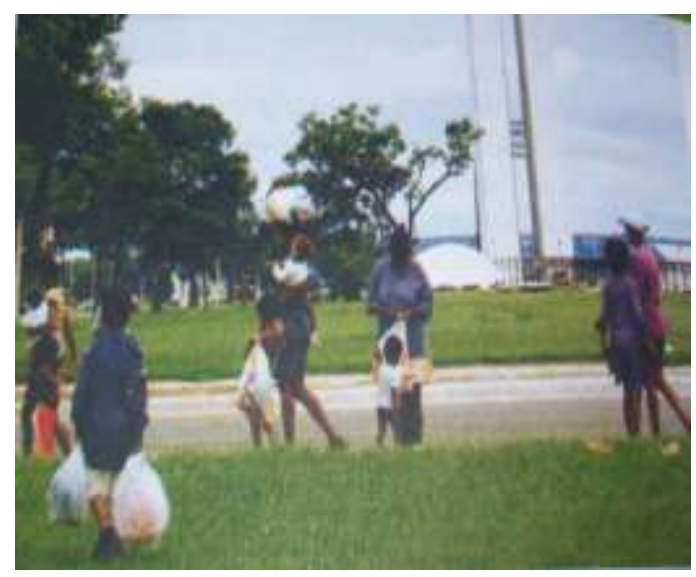

Imagem 1 Pág. 272. 
Nessa imagem podemos perceber claramente que a pobreza tem cor, e a cor da pobreza é negra ${ }^{9}$. Embora a imagem veiculada fale por si só, os autores não vinculam, novamente, fatores simbólicos como contribuidores das condições de pobreza extrema a qual está acometido um grande contingente populacional negro. A questão fica restrita aos altos custos de vida, possibilitando que o leitor se debruce na leitura de forma superficial sobre uma questão que afligiria a todos da mesma maneira, sem se dar conta de questões de cunho simbólico de crucial importância.

A pergunta que imediatamente nos remete é a seguinte: Por que os autores não veicularam além dessas imagens, outras que mostrassem a população negra lutando ativamente em marchas contra o racismo como forma de protesto da condição que assolava o país naquele, e em outros contextos? Uma pergunta que aqui fica sem resposta, mas que podemos elencar várias possibilidades que vão desde a falta de formação para essas questões dos autores, como até a tendenciosidade de não trabalhar essas questões. A pergunta fica mesmo no ar.

De suma importância lembrar que o ano de captação da imagem data de 2003, ano em que fora promulgada a lei n. 10.639 e que já haviam acontecido várias conferências nacionais e internacionais contra o racismo, como é o caso de conferência de Durban, ocorrida em 2001, com a presença do então presidente Fernando Henrique Cardoso.

A não veiculação da resistência negra na história contemporânea do Brasil faz com que tenhamos a impressão de que as lutas negras ficaram perdidas e restritas ao século XIX, pois somente quando se fala em escravização do negro se veicula algum tipo de resistência negra, e mesmo assim localizada em Zumbi e no quilombo dos Palmares. Até as lutas de emancipação do Haiti acabam por ser representadas por negros com ideais europeizados.

\footnotetext{
${ }^{9}$ Que fique claro para o leitor que não estamos generalizando que a pobreza seja fundamentalmente negra, pois um grande contingente de brancos pobres também constitui uma malha da miserabilidade no Brasil. Contudo, não podemos perder de vista que a maioria dos que vivem em condições de miserabilidade são negros e que o imaginário social, por sua vez, faz analogias de que todos os negros provenham da pobreza ou nela permanecem.
} 
Essa maneira de invisibilização acarreta em prejuízo para jovens negros, indígenas e brancos que se pautarão no mito da democracia racial, pois se os negros nada reivindicavam e os problemas do Brasil foram sempre entorno do âmbito econômico e político, não haveria motivo para desconfiar de qualquer racismo velado e institucional, pois racismo seria somente aquilo que fosse abertamente proferido ao outro de maneira manifesta, conforme os livros de história trabalham quando relatam casos como Apartheid na África do Sul, da Klu Klux Klan nos EUA ou do Nazismo alemão.

Seguindo o protocolo e a cronologia dos presidentes os autores entrar no debate acerca dos dois mandados do governo Lula. Logo no início está expresso um panorama geral do governo, com a afirmação de que Lula teria subido ao poder com amplo apelo por justiça social e (re) distribuição de riquezas. Importante relatar que os autores entenderam que a subida de Lula ao poder fora possível via confiança que havia depositada na figura do presidente, por parte de representantes de todas as classes sociais. "A eleição de Lula resultou da consciência mais ou menos disseminada em todo o país ou em todos os grupos sociais da necessidade de mudança, especialmente quanto à distribuição das riquezas". (VINCENTINO, DORIGO, p.275, 2011).

Não partilhamos da mesma ideia dos autores no que concerne a tamanha adesão de setores hegemônicos conservadores da sociedade, pois mesmo que tenha sido uma vitória com um altíssimo percentual de votos, ela foi para o segundo turno sinalizando para uma possível "falta de opção" desses setores no sentido de haver um candidato que os representasse melhor que o candidato a presidente José Serra.

Além disso, somamos o aumento da violência em todo o país no governo de Fernando Henrique Cardoso que gerou um medo nas classes mais abastadas que acreditaram que as políticas sociais manteriam afastados os sujeitos que teoricamente são responsabilizados desse acréscimo de violência do país das áreas onde circulam e/ou residem os mais abastados. Para nós isso não é aventar para distribuição do produto social, pois as políticas públicas implementadas nos locais de maior 
vulnerabilidade social mostra-nos que os efeitos de inserção em mercado de trabalho e/ou de espaços decisórios são irrisórios.

O panorama social do governo é externalizado no texto através da critica de varias políticas públicas como o programa Bolsa Família e o programa Fome Zero. Na página 278 os autores relatam que o empobrecimento e o sucateamento da polícia militar dos estados como um grande fator contribuidor para o agravamento da violência urbana que assola as grandes cidades com gigantescos índices de criminalidade e mortes. Contudo, novamente os autores deixam escapar à possibilidade de racializar a discussão dizendo qual o contingente populacional está mais suscetível à violência urbana e as causas de vulnerabilidade.

Várias leituras seriam possíveis acerca do que está contido no capítulo treze desse livro. Contudo, nos propomos a discutir a omissão de alguns traços importantes acerca da questão racial e as determinações que partem delas para estratificar a hegemonia branca no poder, determinações essas que continuam mantendo o status quo de uma sociedade racista que se diz democrática.

O capítulo finaliza com alguns balanços do governo Lula sempre na direção das ações políticas, econômicas e sociais, mas nunca privilegiando os traços educacionais como viabilizadores da ambivalência da situação a que se encontra o país, pois ao passo que a educação teria a função transformadora para formar sujeitos contestadores de uma ordem política, econômica e social-simbólica perversa, ela também aventa para a possibilidade de formar sujeitos descontextualizados, performáticos e sem sensibilidade para as questões raciais, fruto de assimilação do mito da democracia racial.

Antes de fecharmos essa seção informamos que uma série de testes e exercícios de vestibulares de grandes universidades do Brasil estão no fim do capítulo a fim de trazer a reflexão do educando em relação ao que foi estudado ao longo do livro.

Em um desses exercícios encontramos uma questão interessantíssima, e que na realidade, vem a corroborar com o que estamos discutindo. Cabe lembrar que esse exercício não é uma questão de 
vestibular de nenhuma universidade, e sim é uma questão formulada pelos autores, a saber:

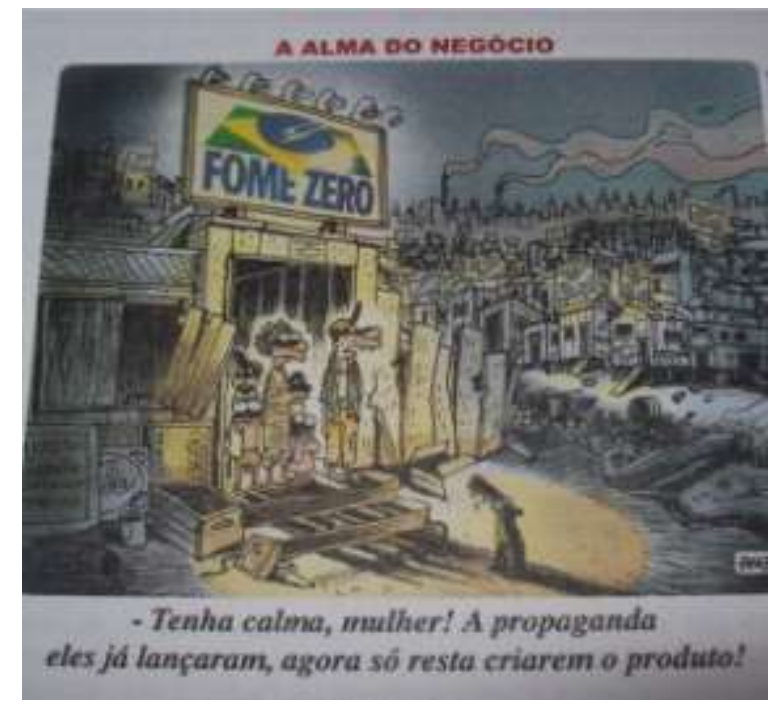

Imagem 2 Pág. 284.

De acordo com o que o autor pede na questão chegamos à conclusão que o que responderia a pergunta sobre quem são os personagens e o que ajudaria ao identificá-los na imagem, estaria intimamente ligada ao que o imaginário social tem em relação à população negra e a vinculação poderia ser de forma instantânea pelo educando, vinculando pobreza e favela aos negros, sendo que em nenhuma parte do texto há aportes racializadores que permitiria que os educandos pudessem cautelosamente contestar a imagem dizendo que grande parcela da população negra constitui o exército dos mais pobres e vulneráveis socialmente, mas que isso não constitui uma generalização que marca pejorativamente os negros, causando efeitos nefastos no mundo das relações simbólicas que dão acesso ao mercado de trabalho, relações interpessoais, estado de vulnerabilidade em relação à violência e etc.

Portanto, a análise, feita por nós, desse livro de História do ensino médio foi realizada no intuito de perceber se há questões subjacentes à representatividade da população negra no que concerne a contextualização no cenário nacional e na estereotipação em textos e imagens comumente veiculado em livros didáticos de diversos segmentos educacionais. 
Textualmente não encontramos, simplesmente, nenhuma referência da população negra no contexto de nenhum dos governantes estudados nesse capítulo treze, como se nenhum tipo de reivindicação ou acontecimento importante em relação às políticas raciais em contexto global e nacional tenha de substancializado, nem o fim do apartheid e seus desdobramentos no Brasil fora citado pelos autores. Quanto à parte imagética somente uma fotografia e uma charge fora veiculada. Contudo, essas veiculações subrepresenta a população negra sempre vinculando a condição de pobreza e miserabilidade por omissão dos governos, como se a população negra, de forma.

\section{Considerações Finais}

Os livros didáticos dialogam extensamente com a sociedade, realidade observável quando refletimos acerca das irradiações de verdades e falsidades expressas nos mais diversos veículos de comunicação da sociedade, moldando o cotidiano e o imaginário social, alcançando até mesmo aqueles que não passaram pelo processo de educação formal, a escola.

A afirmação acima é condicionada a sapiência de que aqueles que possibilitados por uma gama de dispositivos, produzem programas de rádio, Tevê, revistas e até mesmo os conteúdos educacionais, já se escolarizaram, e essa escolarização passou, necessariamente, pelos conhecimentos de livros didáticos, pelos mesmos motivos circulares que estamos descrevendo.

Nesse sentido, nosso estudo buscou demonstrar como o livro didático tem se comportado mesmo após a formulação de uma lei que visou buscar a erradicação de estereótipos clássicos acerca da população negra no que tange textos e imagens em livros didáticos em todos os níveis de ensino.

Chegamos à conclusão de que a sociedade brasileira não tem tido acesso a materiais que explicam com maior minucia porque os negros estão mais suscetíveis a alguns processos de exclusão daquilo que se tem como benesse social, pois esses estariam sub-representados em materiais 
didáticos que, junto com outros veículos de informação, auxiliam na prescrição do aceitável, do previsível e da invenção dos gostos dessa sociedade, que busca moldar seu escopo simbólico no "espelho" da Europa, assimilando discursos ultrapassados e descontextualizados, dificultando, por conseguinte, que o país emirja enquanto nação de fato democrática.

No livro analisado a pretensa dos autores em trazer a tona que alguns motivos pelo qual a nação não avança no plano social têm suas raízes nos planos políticos e econômicos. Para nós, isso constitui uma parte significativa do processo, mas que sem se pensar em questões de ordem simbólicas a supervalorização de uns (cultura, estética e etc.) em detrimento de outros não seria possível.

Pensar que somente as questões de ordem financeira daria conta de equalizar as oportunidades de acesso ao produto social seria para nós, retroceder a ilusão que somos uma nação democraticamente racial e que todos são iguais com oportunidades iguais, ou seja, que o destino de cada sujeito é de responsabilidade individual. Assim, o mérito individual que premiaria o sujeito independente de classe social, raça, credo, gênero, opção sexual ou idade, sem se considerar o contexto em que se passa uma situação pontual.

A representação do outro pode ser mais uma maneira de manipular aquilo que se deseja, ou as normas de socialização que se deseja. As facetas das representações consistem em delegar poder de legitimidade a quem enuncia o discurso e consegue dar uma roupagem verídica e de grande valor discursivo na maior escala possível de irradiação. Representar o outro, por outro lado, pode constituir um processo de repetição daquilo que se têm apreendido sobre as possibilidades do que seja este outro. Representar outro indivíduo nunca dará conta do que o outro individuo é de fato, pois conforme estudamos anteriormente nenhum sujeito tem acesso às ideias ou aquilo que o outro seja de fato.

Contudo, o fato social nos obriga a lidar com questões subjacentes a veiculação de textos e imagens determinadas nos diversos meios de construção do conhecimento. Esse contato que temos, com as representações estabelecidas, é capaz de moldar identidades e de 
prescrever o que é aceitável ou não na sociedade. Esses juízos de valor prejudicam uns e beneficiam outros, automaticamente. Surge a necessidade de (re)construção da imagem daqueles que estão afiliados as representações negativas que os excluem dos espaços decisórios na sociedade. Nosso entender, as representações de uns acerca dos outros devem buscar meramente um apontamento para que a experiência de conhecer o outro ou a cultura do outro faça com que um diálogo respeitoso seja possível. Mas como fazer isso? É tarefa difícil conseguir que um ser humano tenha uma experiência com outro ser humano de forma genuína e sem se influenciar por conhecimentos prévios feitos dentro de si ou em suas experiências mundanas, mas concebemos que há a possiblidade de diálogos mais amistosos e/ou respeitosos na medida em que não comparamos valorativamente uns e outros.

O discurso ocidental se prevaleceu da força de irradiação possibilitada por alguns avanços tecnológicos, que por sua vez veio com a ganancia expansiva de conquista de outros povos, para fortalecer ainda mais a propagação de suas verdades e se expandir mais ainda territorialmente, financeiramente e politicamente o que, por conseguinte, condicionou o estabelecimento enquanto cultura simbolicamente superior. Os territórios dominados pela cultura europeia além de subordinação política, econômica e social, almejam simbolicamente aquele continente em detrimento os países dos continentes ditos atrasados, o que objetivamente produz mais dependência da Europa e conflitos internos que acabam por ser escamoteados em alguns países, como é o caso do Brasil.

A invisibilização do negro no livro didático trabalhado pode constituir um desconhecimento de questões relativas á participação dos negros no produto social, com reivindicações ativas por melhorias no bem estar social por sofrerem com a perversidade do racismo. Se for esse o caso da invisibilização do negro no livro analisado, estamos deparados com uma questão circular em movimento, pois da mesma maneira que os autores não tinham tais informações e não buscaram por entender que elas sejam por menores, o leitor desse estudo também não terão acesso e podem achar que a questão social geral suplanta a questão racial não sendo 
necessária a busca por essa via. Se não for esse o caso da invisibilização do negro nesse livro, a inferência que fazemos é de que se trata de uma estratégia deliberada de apagamento das tensões raciais no país direcionando a questão para o âmbito da democracia racial e da naturalização das vinculações dos negros aos estereótipos que a cada dia se perpetuam.

Portanto, buscamos demonstrar nesse estudo como vem sendo trabalhado os aportes da lei n. 10.639/03 em um livro editado após essa lei e escolhido através do Plano Nacional do Livro Didático do Ensino Médio (PNLDEM), tendo em vista que esse é um ano de escolha de livros a serem utilizados nos próximos três anos. Nossa conclusão, após análise de um capítulo de um livro didático editado para fazer parte da concorrência para que seja o livro implementado em escolas públicas, é a de que a falta de conhecimento da lei n. 10.639/03 aliada ao atraso e ao descaso que se têm no Brasil em relação aos estudos de cultura negra e africana, contribui de forma decisiva para que a sociedade cultive, ainda, estereótipos e imagens negativas do negro na sociedade brasileira, mantendo firme o status quo de uma sociedade onde o poder continua sendo branco, heterossexual e machista, dependesse exclusivamente de políticas públicas governamentais de cunho socioeconômico para superar a condição "natural" de exclusão na qual estariam acometidos ${ }^{10}$.

\section{Referências}

BAUDRILLARD, Jean. A sombra das maiorias silenciosas: O Fim do Social e o Surgimento das Massas. Sabotagem, 2005.

BRASIL, Lei no. 9.394. LDB - Leis de Diretrizes e Bases da Educação Nacional. De 20 de Dezembro de 1996. D.O.U. de 23 de Dezembro de 1996. BRASIL, Lei no. 10.639., de 9 de Janeiro de 2003. D.O.U. de 10/01/2003. BRASIL, Ministério da Educação. Diretrizes Curriculares Nacionais Para a Educação das Relações Étnico-Raciais e para o Ensino de História e Cultura

\footnotetext{
${ }^{10}$ Utilizamos a palavra "natural" para nos referirmos à falta de vinculação aos processos simbólicos racistas impregnados nas instituições públicas e privadas, fruto de um imaginário social racista.
} 
afro-brasileira e Africana. Parecer CNE /CP 3 / 2004, de 10 de março de 2004.

DURKHEIM, Émile. Educação e sociologia. 9 ed. São Paulo: Melhoramentos, $\mathrm{s} / \mathrm{d}$.

Da divisão do trabalho social. São Paulo: Martins Fontes, 1999.

FREYRE, Gilberto. Casa Grande e Senzala. Livraria José Olympio Editora, V.2, 1946.

HEIDEGGER, M. Identidade e diferença. O princípio da identidade e constituição onto-teo-lógica da metafísica. São Paulo: Ed. Abril. Coleção os Pensadores, 1973.

M. Sobre o Fundamento da Verdade. Ed. Abril. Coleção os

Pensadores, 1973.

MAINGUENEAU, Dominique. A propósito do Ethos. In. MOTTA, Ana Raquel \& SALGADO, Luciana. (Orgs.). Ethos Discursivo. São Paulo: Contexto, 2008.

MUNANGA, Kabengele. Argumentos a favor das cotas raciais. In: SILVA, Petronilha Beatriz Gonçalves e; SILVÉRIO, Valter Roberto (Orgs.). Educação e ações afirmativas: Entre a violência simbólica e a injustiça econômica. Brasília: Instituto Nacional de Estudos e Pesquisas Educacionais Anísio Teixeira, 2003.

. Uma abordagem Conceitual das noções de Raça, Racismo, Igualdade e Etnia. Palestra proferida no 30 Seminário Nacional de Relações Raciais e Educação - PENESB - RJ 05/11/2003. Disponível em:

http://www.acaoeducativa.org.br/downloads/09abordagem.pdf.

- Rediscutindo a Mestiçagem no Brasil: Identidade Nacional Versus Identidade Negra. 3 ed. Belo Horizonte: Autêntica. 2004.

Apresentação. In: BRASIL, Superando o racismo na escola.

MUNANGA, Kabengele (org.). Brasília: MEC / SECAD, 2008, p. 11-16.

Teoria Social e Relações Raciais No Brasil Contemporâneo.

Cadernos Penseb, n. 12, 2010.

OLIVEIRA, I. ; SACRAMENTO, M. P. Raça, currículo e práxis pedagógica e Relações raciais e educação: o diálogo teoria/prática na formação de profissionais do magistério. Cadernos PENESB, v. 1, p. 209-289, 2010.

RAMOS, G. O Negro Desde Dentro. In: Ensaio em Teatro experimental do Negro.Testemunhas. Edições GRD, 1966.

SILVA, A. C. da. A discriminação do negro no livro didático. Salvador: CEAO /CED. 1995.

Desconstruindo a discriminação do negro no livro didático.

Salvador: EdUFBA, 2001.

. A Desconstrução da Discriminação no Livro Didático. In: MUNANGA, Kabengele (Org.). Superando o Racismo na Escola. 2 ed. MEC / BID / UNESCO. Brasília, 2005. 
SODRÉ, Muniz. Claros e Escuros: Identidade, povo e mídia no Brasil. Petrópolis: Vozes, 2000.

. O Social Irradiado:Violência Urbana, Neogrotesco e Mídia. São

Paulo: Cortez Editora, 1992.

A verdade Seduzida. Rio de Janeiro: Francisco Alves, 1984. O monopólio da fala. Função e Linguagem da Televisão no Brasil.

Petrópolis: Vozes, 1989.

A máquina de Narciso. Televisão, Indivíduo e Poder no Brasil. 3 ed. Cortez Editora, 1990.

Antropológica do Espelho. Uma Teoria da Comunicação Linear em Rede. Petrópolis. RJ: Editora Vozes, 2002.

VICENTINO, C.; DORIGO, G. História Geral e do Brasil. v. 3, São Paulo: Editora Scipione, 2011.

Enviado pelo autor em 09 de Maio de 2012.

Aprovado em 31 de Agosto de 2012. 